\title{
Stress Monitoring for Anchor Rods System in Subway Tunnel Using FBG Technology
}

\author{
Xiaolin Weng, Haohao Ma, and Jun Wang \\ Key Laboratory for Special Area Highway Engineering of Ministry of Education, Chang'an University, Xian, Shaanxi 710064, China \\ Correspondence should be addressed to Xiaolin Weng; 49768532@qq.com
}

Received 7 October 2014; Revised 1 February 2015; Accepted 4 February 2015

Academic Editor: Hemmige S. Yathirajan

Copyright (C) 2015 Xiaolin Weng et al. This is an open access article distributed under the Creative Commons Attribution License, which permits unrestricted use, distribution, and reproduction in any medium, provided the original work is properly cited.

\begin{abstract}
This paper presents a model test, used on the tunnels on Xi'an Metro Line 2, as the prototype for evaluating the reinforcing effect of the anchor rod in tunnel construction in loess areas. An independently designed fiber Bragg grating (FBG) sensor was used to monitor the seven strain conditions of the rock bolts during the construction. The result shows that the axial stress of the rock bolt changes after the excavation and increases steadily with the growing pressure in the wall rock. Results additionally show that the anchor rods at the tunnel vault are subjected to a compressive stress that remains relatively constant after the primary and the secondary lining, while those at the spandrel and the corner of the tunnel are subjected to increased tensile stress. This paper demonstrates the feasibility and the superiority of FBG technology for tunnel model tests.
\end{abstract}

\section{Introduction}

Assessing the condition and monitoring the health of structures make up an integral part of civil engineering, where there is an ongoing need to estimate the response of structures under particular loading and environmental conditions [1, 2]. Health monitoring is also used as a diagnostic tool by which engineers not only detect or infer the presence of defects but also schedule maintenance operations. Civil structures can be assessed by established techniques such as ultrasonic scanning [3], transient pulse and infrared thermography $[4,5]$, and ground radar $[6,7]$. Despite being adequate and reliable, these conventional techniques are not suitable for real-time, in situ assessment of structures. These limitations can be overcome by using electrical-resistance strain gauges $[2,8]$, acoustic emission $[9,10]$, or optical fiber sensors [11-13]. The advantages associated with optical fiber sensors, over conventional monitoring techniques, include their immunity to electromagnetic interference; their small size and lightweight construction; and the access they facilitate to different measurements, such as strain, temperature, vibration, and specified chemicals. The optical fiber sensors can also be multiplexed, meaning that more than one sensor can be integrated along a single optical fiber. One can monitor the distributed mapping of a structure thanks to this multiplexing capability [14]. When the optical sensors will be used in physically and chemically harsh environments, strategies for sensor protection and bonding must be developed in order to monitor structures in the long term while ensuring reliable measurements.

In 1978, Hill et al. first discovered the photosensitivity of the optical fiber, a discovery that eventually led to the occurrence of the fiber grating [15]. The application of this device as a sensor was first reported by Morey late in 1989. In the ensuing years, the fiber grating sensor went through rapid development and drew worldwide attention; it is now widely used in many industries. It was also in 1989 that, for the first time, the fiber grating sensor was proposed [16]. By far a number of tests regarding application of FBG technology have been reported in engineering respect. For instance, a FBG-based concrete model quasi-static test was made on Donghai Bridge, and a study was developed concerning the application of FBG technology in the health monitoring of large bridges [17]. Fiber grating sensor modules were embedded in the three-dimensional geomechanical model of a bifurcate tunnel, which has successfully performed strain monitoring during tunnel excavation [18]. Along with Brillouin optical time domain reflectometry (BOTDR), fiber 

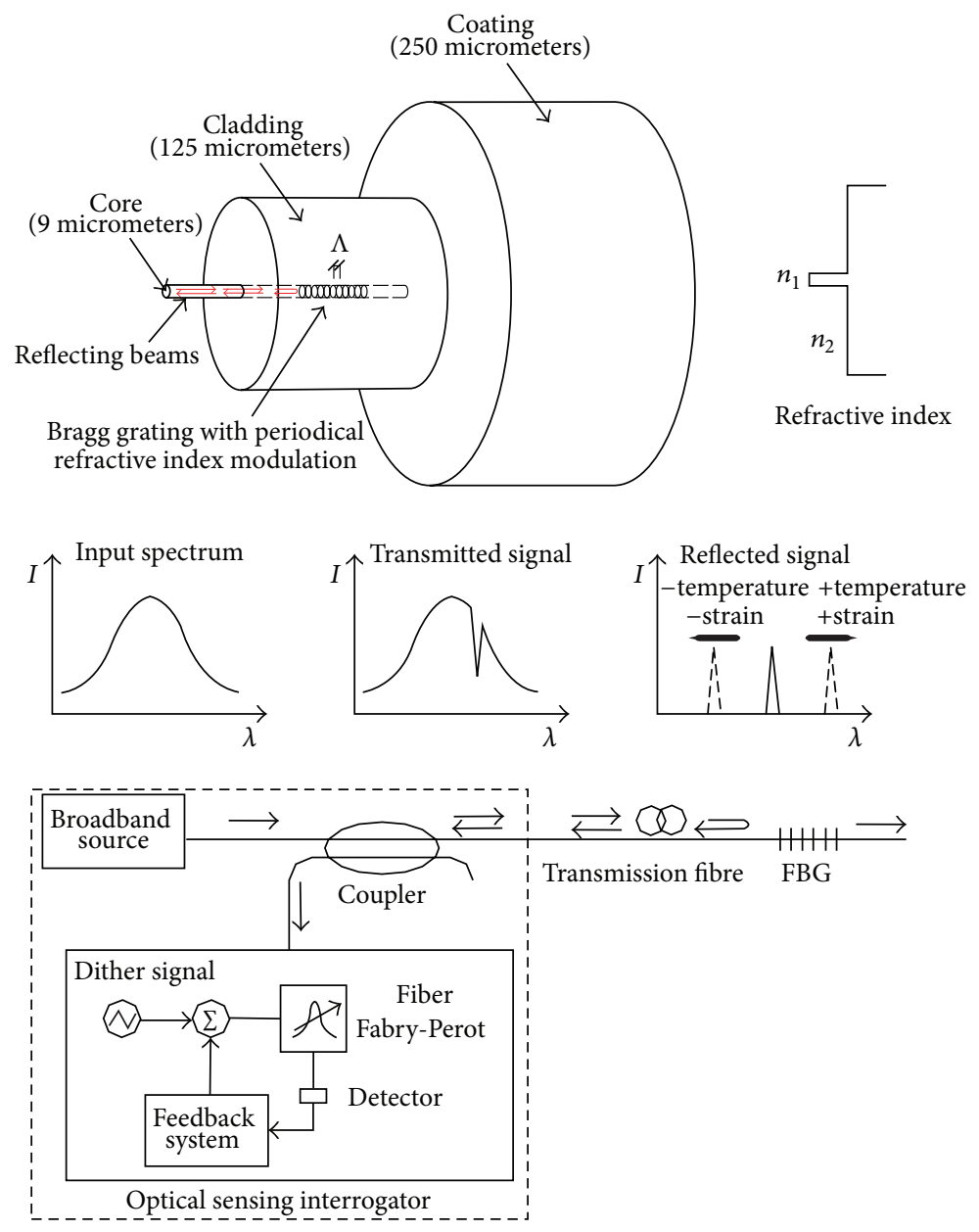

FIGURE 1: Strain and temperature sensing of an FBG sensor.

grating sensors were used to monitor the deformation of a slope model, effectively proving the advantages and prospects of both for engineering application [19].

The FBG-based model test-applied to the subway tunnel in a loess area-presented in this paper validates the reinforcing effect of the anchor rods.

\section{Working Principle of Fiber Grating}

The sensing functioning of fibre Bragg grating (FBG) was firstly discovered on the formation of photogenerated gratings in germanosilicate optical fibre by Hill et al. [20]. The Bragg grating is written into a segment of Ge-doped singlemode fibre in which a periodic modulation of the core refractive index is formed by exposure to a spatial pattern of ultraviolet (UV) light. Figure 1 illustrates the working principle of an FBG sensor. According to Bragg's law, when a broadband source of light has been injected into the fibre, FBG reflects a narrow spectral part of light at a certain wavelength [21]:

$$
\lambda_{B}=2 n_{\mathrm{eff}} \Lambda
$$

where $\lambda_{B}$ is the Bragg wavelength, typically 1510 to $1590 \mathrm{~nm}$ $\left(1 \mathrm{~nm}=10^{-9} \mathrm{~m}\right), n_{\text {eff }}$ is the effective core index of refraction, and $\Lambda$ is the period of the index modulation.

Through physical or thermal elongation of the sensor segment and through the change in the refractive index of the fibre due to photoelastic and thermooptic effect, the Bragg wavelength will change linearly with strain and temperature. Considering a standard single-mode silica fibre, $\lambda_{B}$ changes linearly with the applied strain $\Delta \varepsilon$ and temperature $\Delta T$. This relationship is given by [22]

$$
\frac{\Delta \lambda_{B}}{\lambda_{B 0}}=c_{\varepsilon} \varepsilon+c_{T} \Delta T,
$$

where $\lambda_{B}$ is the original Bragg wavelength under strain-free and $0^{\circ} \mathrm{C}$ condition, $\Delta \lambda_{B}$ is the variation in Bragg wavelength due to the applied strain and temperature, and $c_{\varepsilon}$ and $c_{T}$ are the calibration coefficients of strain and temperature. The typical strain and temperature accuracy of a bare FBG sensor are $1 \mu \varepsilon$ and $0.1^{\circ} \mathrm{C}$, respectively.

As the FBG sensor is sensitive for both strain and temperature, how to separate the effect of temperature from the strain monitoring data is a key problem in data analysis. This temperature compensation problem can be achieved 
by adding an additional FBG sensor or a conventional temperature sensor to the same temperature field. Once the temperature $\Delta T$ is measured, the mechanical strain can be corrected as follows:

$$
\Delta \varepsilon=\frac{1}{c_{\varepsilon}}\left(\frac{\Delta \lambda_{B}}{\lambda_{B}}-c_{T} \Delta T\right) .
$$

\section{Tunnel Model and Test}

3.1. Tunnel Model. According to the similarity criteria for model test, the loessial soil on the site of Xi'an Metro Line 2 was selected as the wall rock material. It has an internal frictional angle of $20^{\circ}$, a cohesive strength of $0.045 \mathrm{MPa}$, and Poisson's ratio of 0.31 . Plaster was used to simulate the reinforcing concrete for the tunnel lining, which has an elastic modulus of $3.5 \mathrm{GPa}$ with a water-to-plaster ratio of 1.0. In accordance with the similarity criteria for bending deflection, the model lining was constructed with a thickness of $2 \mathrm{~cm}$ to simulate the $60 \mathrm{~cm}$ thick prototype. The anchor rod of the prototype was $22 \mathrm{~mm}$ in diameter and $3500 \mathrm{~mm}$ in length. Based on the similarity criteria, the tin-solder model anchor rod was constructed to be $1.5 \mathrm{~mm}$ in diameter and $70 \mathrm{~mm}$ in length.

Normally, the application of anchor rods in real tunnel construction primarily includes the drilling of holes, rod installation, and grouting. This practice, however, was not followed in the model test because of size limit. Instead, the wall rock material was placed up to the design location of the anchor rod, and then a cylinder (with a diameter twice that of the anchor rod) was embedded as the "hole" into which the anchor rods were then installed and grouted. The placement of wall rock would be followed.

The model test was performed by use of a PDY-50 model tester, which is composed of a supporting system, a hydraulic loading system, and a measuring system; this model tester enables three-dimensional loading. To simulate real tunnel construction, a preload equivalent to the stress in the original rock was applied to the model to obtain an initial deformation and the excavation, which was followed immediately by tunnel lining. The excavation was simulated approximately by taking out the wood former embedded beforehand in the model.

3.2. Packaging of Fiber Grating Sensor. A fiber grating sensor was independently designed and produced for this model test. The sensor head was adhered with " 502 " glue to the surface of the tin-solder rod, and the fiber was wrapped up with four layers of thermal plastic pipe. This simple package, according to experiment, has greatly improved the serviceability rate of the fiber grating, which remains over $80 \%$, even after a destructive test. As for the fiber grating of the model test, all were undamaged in wall rock placement and only several broke in the end, due to excessive load; an overall serviceability rate of $90 \%$ was eventually obtained. Figure 2 shows a packaged fiber Bragg grating with a grating length of $10 \mathrm{~mm}$ and a spacing of $5 \mathrm{~mm}$. To ensure a quasi-distributed measurement, two sensors were installed in series on each anchor rod. The test applied a SM125 optical demodulator

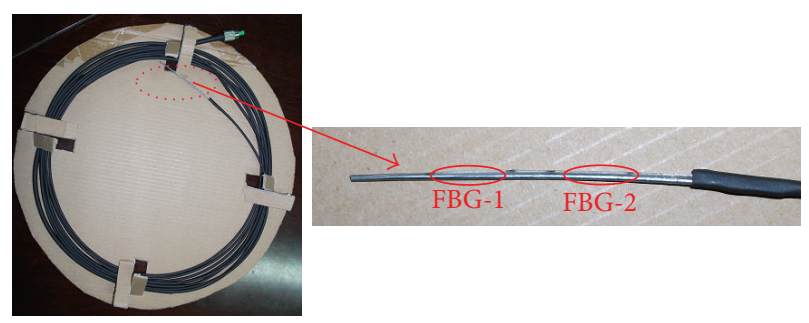

FIGURE 2: Packaged fiber Bragg grating sensors.

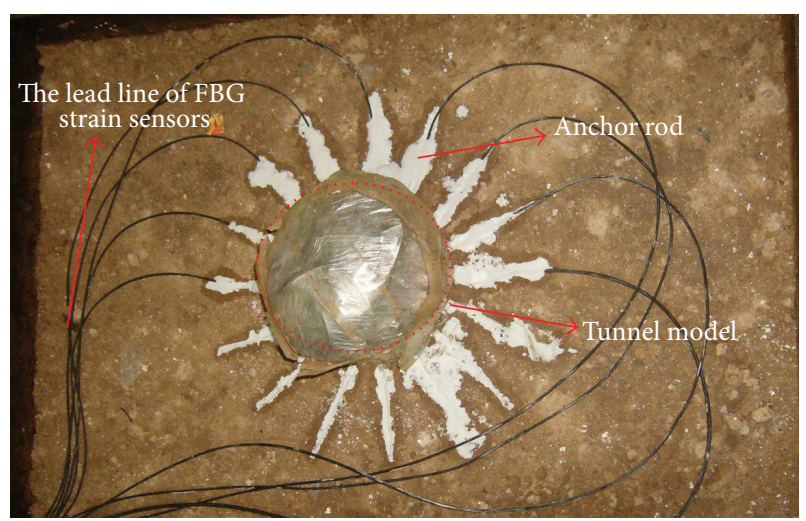

FIGURE 3: Anchor rods installed in place.

of $\mathrm{MO}$, and ALTECO AB glue was used for the adhesion between the fiber and the anchor rod.

3.3. Embedding of Fiber Grating Sensors. The installation of the anchor rod was carried out in the following procedures:

(1) preparation of anchor holes,

(2) injection of grout,

(3) installation of anchor rods,

(4) fixing of anchor rods.

As previously mentioned, it is hard to install the anchor rod after the excavation; instead, these rods are embedded beforehand during wall rock placement. In consideration of the fragile optical fiber, caution must be taken to avoid a too small bending angle, and the wall rock must be free of coarse soil particles. Figure 3 shows the anchor rods installed in place.

The adapter between the fiber and demodulator must be carefully protected, as it directly relates to the serviceability of the fiber grating. To ensure that the adapter remained clean and secure, the thermal plastic pipe was extended to cover the adapter during the packaging of fiber grating, and it was sealed with a rubber sheath. To ensure the coaction with the fiber grating, prior to being embedded, the anchor rod was hooked in the end closest to the cave and then stretched after the excavation. The primary lining was simulated by injecting plaster grout (with a water-to-plaster ratio of 1) into the gap between the cave and the secondary lining, which had been already put in place. 


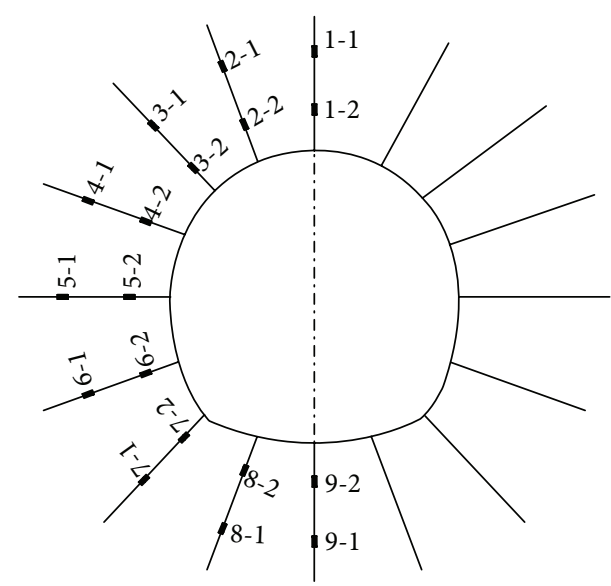

(a) Pattern A in full section

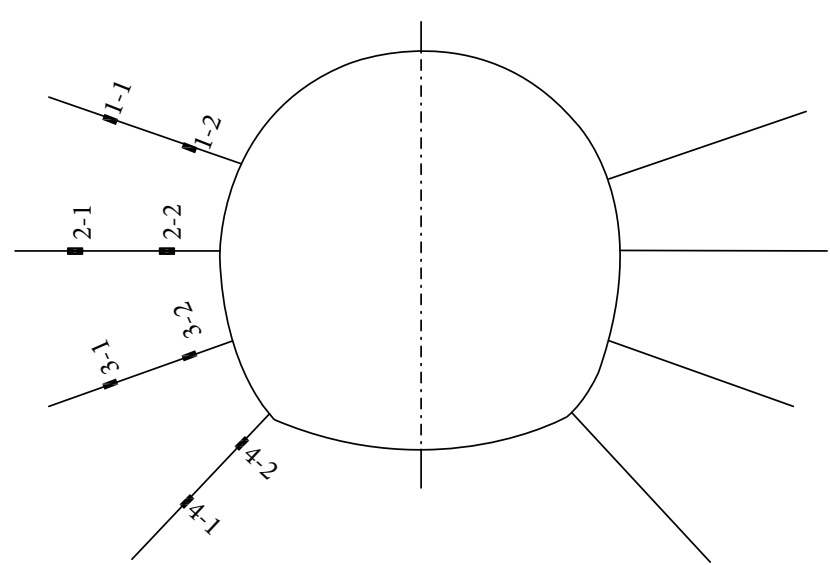

(b) Pattern B in partial section

Figure 4: Arrangement of anchor rods.

3.4. Test Process. Two typical sections of Xian Metro Line 2-one at K6+997 between the library and Daming Palace and the other at K15+346.5 between Yongningmen and Nanshaomen-were selected as the prototype cross section. To evaluate the effect of the anchor rods in shallowly buried weak rock, they were arranged in two patterns for each group, namely, full section (Pattern A) and partial section (Pattern $B)$, which are, respectively, numbered M-A and M-B. For the monitoring of strain variation, two fiber grating sensors were installed in series on each anchor rod, as shown in Figure 4. For number 1 anchor rod in two patterns, FBG 1 and FBG 2 are, respectively, numbered 1-1 and 1-2, as shown in Figure 4.

As previously stated, to simulate the real situation, a preload equivalent to the stress in the original rock was applied to the model prior to the excavation; in this way, the initial deformation was obtained. The preload was increased from $0.3 \mathrm{MPa}$ in a step of $0.1 \mathrm{MPa}$ until it reached $0.5 \mathrm{MPa}$. After one hour of rest, the cave excavation was started. The cave was designed with sufficient space for the primary and secondary lining. The excavation was approximately simulated via removal of the wood former, embedded beforehand in the model. The precast secondary lining was put in the cave and then plaster grout was injected into the gap to simulate the primary lining. After the completion of tunnel lining, the load was continuously increased and applied to the model until destruction occurred. A SM125 demodulator kept a realtime record of the data of the fiber Bragg grating sensors.

\section{Test Results Analysis}

The stress of anchor rods can be obtained through the calculation with the following equation:

$$
\sigma=E \varepsilon
$$

where $E$ is the modulus of anchor rods.

Stress analysis consists of seven typical stress conditions, which occurred successively in the model test: Stage 1 is the initial state (i.e., immediately after the application of the initial stress), Stage 2 is before the excavation, Stage 3 is after the excavation, Stage 4 is after the primary lining, Stage 5 is after the secondary lining, Stage 6 is crack-resistance limit state, Stage 7 is failure limit state. A great amount of test data was obtained, part of which is shown in Table 1 and Figure 5.

According to Table 1 and Figure 5, the axial stress of the anchor rod changed after the excavation and increased steadily with the growing pressure in the wall rock. In Group $\mathrm{M}-\mathrm{A}$, anchor rods $1,2,3,8$, and 9 were subjected to a compressive stress, which remained substantially unchanged after the primary and secondary lining and started to increase when the model was overloaded until wall rock failure occurs. In contrast, anchor rods 4, 5, 6, and 7 were subjected to a tensile stress that experienced little change after the excavation and started to increase after the tunnel lining. It can be seen that the anchor rods at the spandrel and the corner of the tunnel, as arranged in Pattern A, were subjected to a tensile stress and exhibited a stronger reinforcing effect than those in other positions. The anchor rods at the vault, however, experienced little stress change after the excavation, which implicates an unobvious reinforcement. By comparing test results obtained at different water content, it can also be found that the stress of the anchor rod in wall rock of higher water content has greater change after the excavation, which means that the anchor rod plays a more effective role in the wall rock of inferior quality. Meanwhile, in Group M-B, the four anchor rods experienced a low level of compressive stress and then a tensile stress before and after the excavation. The axial stress remained substantially unchanged after the primary lining but started to increase after the secondary lining until wall rock failure occurred. This indicates that the anchor rod can provide a more effective reinforcement and improve the stability of the supporting system, especially when the tunnel lining develops cracks.

\section{Numerical Analysis of Anchor Rods}

5.1. Finite Element Model. Using a plane elastic-plasticity finite element, an analog computation was made based on 
TABLE 1: Test results of Group M-A (unit: kN).

\begin{tabular}{|c|c|c|c|c|c|c|c|}
\hline & Stage 1 & Stage 2 & Stage 3 & Stage 4 & Stage 5 & Stage 6 & Stage 7 \\
\hline $1-1$ & -0.31 & -3.27 & -3.24 & -2.07 & -2.50 & -3.52 & -21.56 \\
\hline $1-2$ & -0.59 & -4.35 & -4.32 & -2.79 & -3.32 & -6.48 & -33.55 \\
\hline $2-1$ & -0.40 & -2.80 & -2.80 & -2.50 & -2.68 & -4.77 & -33.21 \\
\hline $2-2$ & -0.56 & -3.03 & -3.06 & -2.84 & -2.97 & -7.40 & -40.91 \\
\hline $3-1$ & -0.05 & 0.68 & 0.65 & 0.47 & 0.62 & -3.77 & -12.38 \\
\hline $3-2$ & -0.06 & 0.32 & 0.25 & 0.12 & 0.25 & -1.62 & -8.21 \\
\hline $4-1$ & -0.06 & 0.62 & 0.59 & 0.71 & 2.31 & 3.05 & 13.27 \\
\hline $4-2$ & -0.08 & 0.57 & 0.56 & 0.43 & 2.21 & 4.65 & 17.30 \\
\hline $5-1$ & 0.40 & 3.91 & 3.89 & 5.56 & 4.36 & 5.96 & 9.27 \\
\hline $5-2$ & 0.40 & 3.67 & 3.67 & 4.73 & 4.11 & 4.57 & 13.07 \\
\hline $6-1$ & 0.37 & 2.18 & 2.27 & 3.35 & 2.30 & 7.83 & 25.91 \\
\hline $6-2$ & 0.31 & 2.06 & 2.03 & 2.59 & 2.25 & 5.67 & 30.81 \\
\hline $7-1$ & -0.19 & 0.50 & 0.48 & 1.46 & 0.55 & 3.57 & 2.34 \\
\hline $7-2$ & -0.47 & 0.87 & 0.90 & 1.81 & 1.05 & 7.78 & 16.45 \\
\hline $8-1$ & -1.01 & -2.05 & -2.07 & -1.44 & -2.15 & -11.75 & -43.59 \\
\hline $8-2$ & -1.16 & -2.19 & -2.17 & -1.64 & -2.23 & -11.80 & -42.12 \\
\hline $9-1$ & -0.77 & -3.24 & -3.27 & -2.98 & -3.20 & -5.67 & -22.42 \\
\hline $9-2$ & -0.97 & -3.53 & -3.56 & -3.24 & -3.46 & -8.27 & -36.81 \\
\hline
\end{tabular}

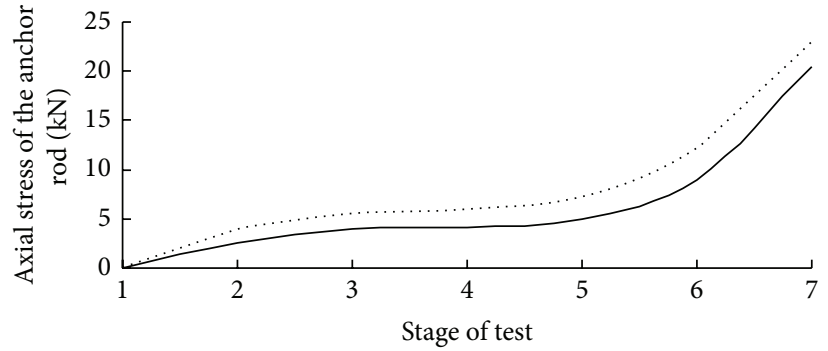

- Fiber grating-1

Fiber grating-2

(a) Number 1 anchor

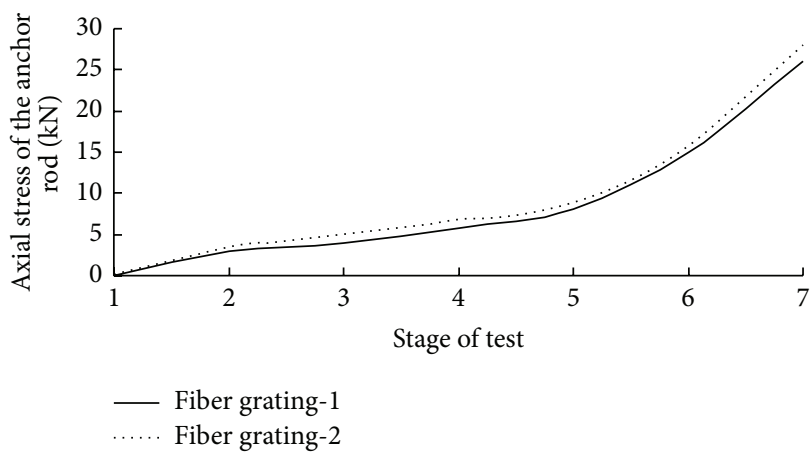

(c) Number 3 anchor

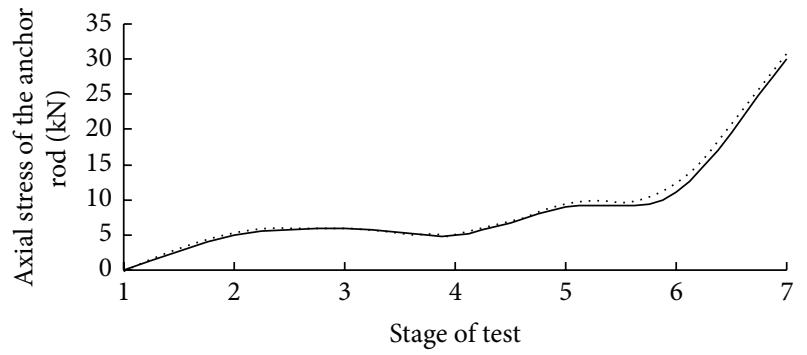

— Fiber grating-1

Fiber grating-2

(b) Number 2 anchor

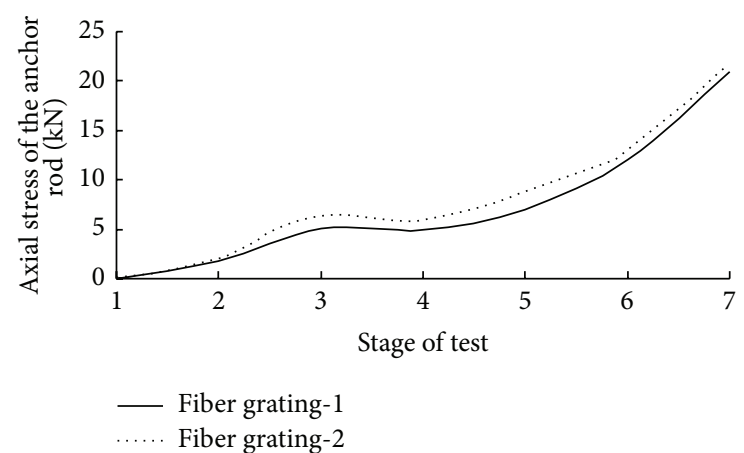

(d) Number 4 anchor

FIgURE 5: Test results of Group M-B.

the mechanical properties of the wall rock of Pattern B. The boundary size ranged from the bottom of the tunnel up to the original ground, with a horizontal distance four times the diameter of the tunnel. The calculation was made on the premise that soils in different stratum are deemed, in whole, as homogeneous. The wall rock and tunnel lining were both simulated by plane isoparametric elements. Specifically, the anchor rod was simulated by a bar element, the tunnel lining by a beam element, and the wall rock by a plane element. Parameters are given in Table 2. 
TABle 2: Parameters of wall rock and tunnel lining.

\begin{tabular}{lccccc}
\hline Name & Specific gravity & Elasticity modulus/GPa & Poisson's ratio & Cohesion/kPa & Internal frictional angle $/^{\circ}$ \\
\hline Wall rock & 1.78 & 0.027 & 0.35 & 34 & 26 \\
Wall rock & 2.5 & 30 & 0.20 & 2420 & 54 \\
Anchor rod & 5.23 & 100 & 0.25 & Diameter: $80 \mathrm{~mm}$ \\
\hline
\end{tabular}

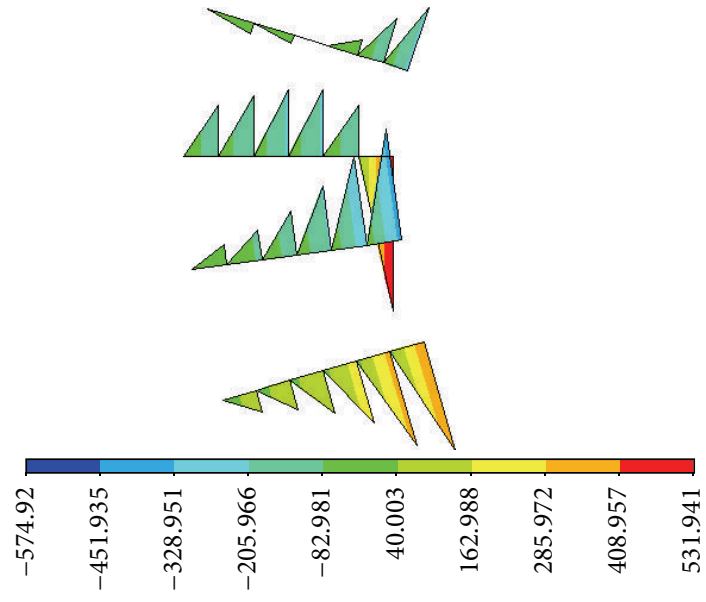

FIgURE 6: Axial force diagram after excavation.
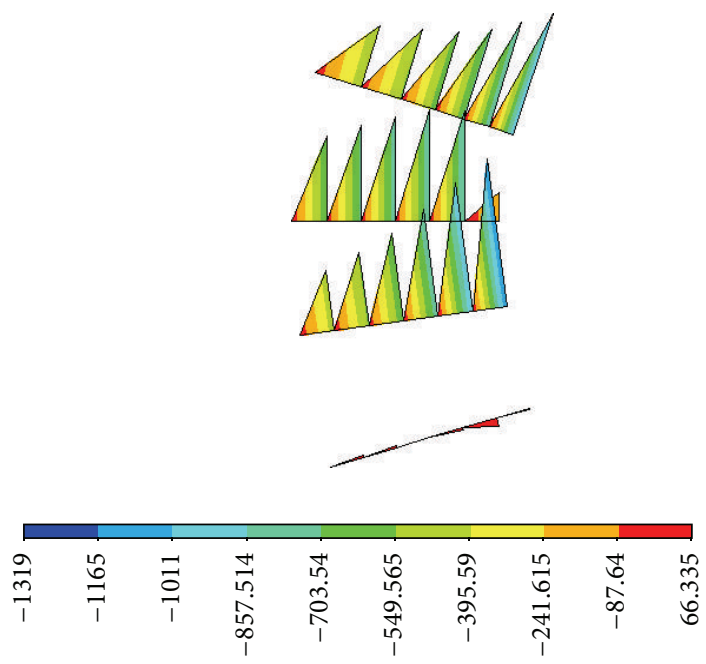

Figure 7: Axial force diagram after the secondary lining.

5.2. Analysis of the Axial Force on the Anchor Rods. The results of numerical analysis are shown in Figures 6 and 7. According to Figure 6, the anchor rods at the spandrel and the sidewall (i.e., Anchor rod 1 and Anchor rod 3 in Pattern B) were subjected to a compressive stress that decreased longitudinally into the rock. Meanwhile, the anchor rod at the arch foot (Anchor rod 2 in Pattern B) was subjected to a tensile stress near the primary lining, which turned into compressive with the increase of the anchorage depth and reached a peak value at the midpoint of the rod. As for the anchor rods in the corner (Anchor rod 3 in Pattern B), due to the settlement between the wall rock (on the left) and the tunnel lining, these rods were all subject to a tensile stress.

In Figure 7, the four anchor rods were subjected to compressive stress after the placement of the secondary lining-except for that in the arch foot (Anchor rod 2 in Pattern B), in which a minor tensile stress developed near the primary lining. The three anchor rods-located at the spandrel, in the arch foot, and near the sidewall (Anchor rods 1, 2, 3 in Pattern B)-were essentially subjected to the same axial force, and the anchor rod in the corner (Anchor rod 4 in Pattern B) was subjected to a minor axial force that decreased along the rod into rock. A comparison between Figures 6 and 7 reveals that the increase of the axial force on the anchor rods after the secondary lining is mainly caused by the restraint to the deformation of the wall rock (on the right).

In comparison of the numerical analysis results, the proposed FBG-based sensor assembly monitored the strain distribution of the anchor rods effectively, which proves it is a promising solution for strain monitoring in subway tunnel.

\section{Conclusions}

According to these test results-obtained by the independently designed fiber Bragg grating sensor for stress monitoring during tunnel construction-the anchor rods at the spandrel and the corner of the tunnel, as arranged in Pattern A, exhibit a better reinforcing effect than those in other positions; and the anchor rods at the vault experience little change in stress after the excavation, which implicates an unobvious reinforcement. As for Pattern B, the anchor rods can provide a more effective reinforcement and improve the stability of the supporting system especially when the tunnel lining begins to crack. The fiber grating sensor shows impressive stability and reliability in stress monitoring for the anchor rods. Furthermore, the test results are proved to be basically in conformity with the mechanical laws. This paper demonstrates the broad prospects of the application of fiber grating sensors in subway tunnel tests.

\section{Conflict of Interests}

The authors declare that there is no conflict of interests regarding the publication of this paper.

\section{References}

[1] Y. B. Lin, C. L. Pan, Y. H. Kuo, K. C. Chang, and J. C. Chern, "Online monitoring of highway bridge construction using fiber Bragg grating sensors," Smart Materials and Structures, vol. 14, no. 5, pp. 1075-1082, 2005. 
[2] T. Matsumoto, P. Kitiyodom, H. Matsui, and Y. Katsuzaki, "Monitoring of load distribution of the piles of a bridge during and after construction," Soils and Foundations, vol. 44, no. 4, pp. 109-117, 2004.

[3] F. Bastianini, A. di Tommaso, and G. Pascale, "Ultrasonic non-destructive assessment of bonding defects in composite structural strengthenings," Composite Structures, vol. 53, no. 4, pp. 463-467, 2001.

[4] M. R. Clark, D. M. McCann, and M. C. Forde, "Application of infrared thermography to the non-destructive testing of concrete and masonry bridges," NDT and E International, vol. 36, no. 4, pp. 265-275, 2003.

[5] H. Wiggenhauser, "Active IR-applications in civil engineering," Infrared Physics and Technology, vol. 43, no. 3-5, pp. 233-238, 2002.

[6] M. Scott, A. Rezaizadeh, A. Delahaza et al., "A comparison of nondestructive evaluation methods for bridge deck assessment," NDT and E International, vol. 36, no. 4, pp. 245-255, 2003.

[7] C. Maierhofer, "Nondestructive evaluation of concrete infrastructure with ground penetrating radar," Journal of Materials in Civil Engineering, vol. 15, no. 3, pp. 287-297, 2003.

[8] C. Cremona and J. Carracilli, "Development and use of smart acquisition systems for bridge monitoring," Key Engineering Materials, no. 204-205, pp. 47-56, 2001.

[9] K. Kageyama, H. Murayama, I. Ohsawa et al., "Acoustic emission monitoring of a reinforced concrete structure by applying new fiber-optic sensors," Smart Materials and Structures, vol. 14, no. 3, pp. S52-S59, 2005.

[10] M. Shigeishi, S. Colombo, K. J. Broughton, H. Rutledge, A. J. Batchelor, and M. C. Forde, "Acoustic emission to assess and monitor the integrity of bridges," Construction and Building Materials, vol. 15, no. 1, pp. 35-49, 2001.

[11] W. Zhang, J. Q. Gao, B. Shi, H. L. Cui, and H. Zhu, "Health monitoring of rehabilitated concrete bridges using distributed optical fiber sensing," Computer-Aided Civil and Infrastructure Engineering, vol. 21, no. 6, pp. 411-424, 2006.

[12] B. Glisic, D. Inaudi, and C. Nan, "Pile monitoring with fiber optic sensors during axial compression, pullout, and flexure tests," Transportation Research Record, no. 1808, pp. 11-20, 2002.

[13] J. M. Lopez-Higuera, C. J. Misas, A. Q. Incera, and J. E. Cuenca, "Fiber optic civil structure monitoring system," Optical Engineering, vol. 44, no. 4, Article ID 044401, 2005.

[14] R. L. Idriss, M. B. Kodindouma, A. D. Kersey, and M. A. Davis, "Multiplexed Bragg grating optical fiber sensors for damage evaluation in highway bridges," Smart Materials and Structures, vol. 7, no. 2, pp. 209-216, 1998.

[15] K. O. Hill, Y. Fuji, C. D. Johnson, and B. S. Kawasaki, "Photosensitivity in optical fiber waveguide: application to reflection filters fabrication," Applied Physics Letters, vol. 32, no. 10, pp. 647-649, 1978.

[16] A. Mendez, T. F. Morse, and F. Mendez, "Applications of embedded optical fiber sensors in reinforced concrete buildings and structures," in 2nd Fiber Optic Smart Structures and Skins, vol. 1170 of Proceedings of SPIE, pp. 60-69, Boston, Mass, USA, February 1990.

[17] R. J. Sun, L. M. Sun, and Z. Sun, "Application of FBG sensing technologies to large bridge structural health monitoring," Journal of Tongji University (Natural Science), vol. 36, no. 2, pp. 149-153, 2008.
[18] T. Chang, D. Li, Q. Sui, and L. Jia, "Experiment research of fiber grating sensor in the forked tunnel model," Chinese Journal of Scientific Instrument, vol. 29, no. 1, pp. 103-108, 2008.

[19] H.-Q. Li, H.-Y. Sun, and Y.-L. Liu, "Application of optical fiber sensing technology to slope model test," Chinese Journal of Rock Mechanics and Engineering, vol. 27, no. 8, pp. 1703-1708, 2008.

[20] K. O. Hill, B. Malo, F. Bilodeau, D. C. Johnson, and J. Albert, "Bragg gratings fabricated in monomode photosensitive optical fiber by UV exposure through a phase mask," Applied Physics Letters, vol. 62, no. 10, pp. 1035-1037, 1993.

[21] W. W. Morey, G. Meltz, and W. H. Glenn, "Fiber optic bragg grating sensors," in Fiber Optic and Laser Sensors VII, vol. 1169 of Proceedings of SPIE, pp. 98-107, Boston, Mass, USA, September 1989.

[22] A. D. Kersey, M. A. Davis, H. J. Patrick et al., "Fiber grating sensors," Journal of Lightwave Technology, vol. 15, no. 8, pp. 1442-1462, 1997. 

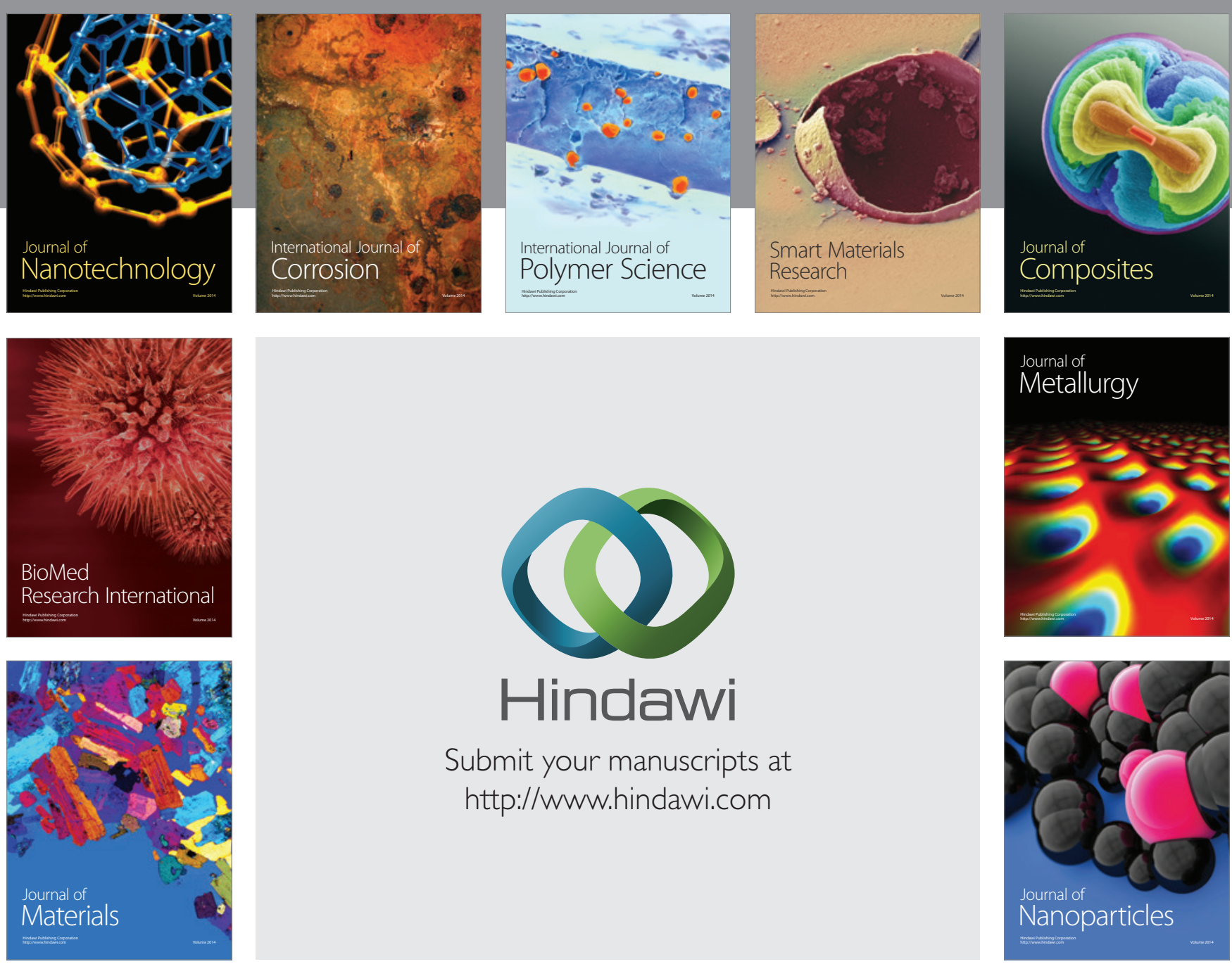

Submit your manuscripts at http://www.hindawi.com
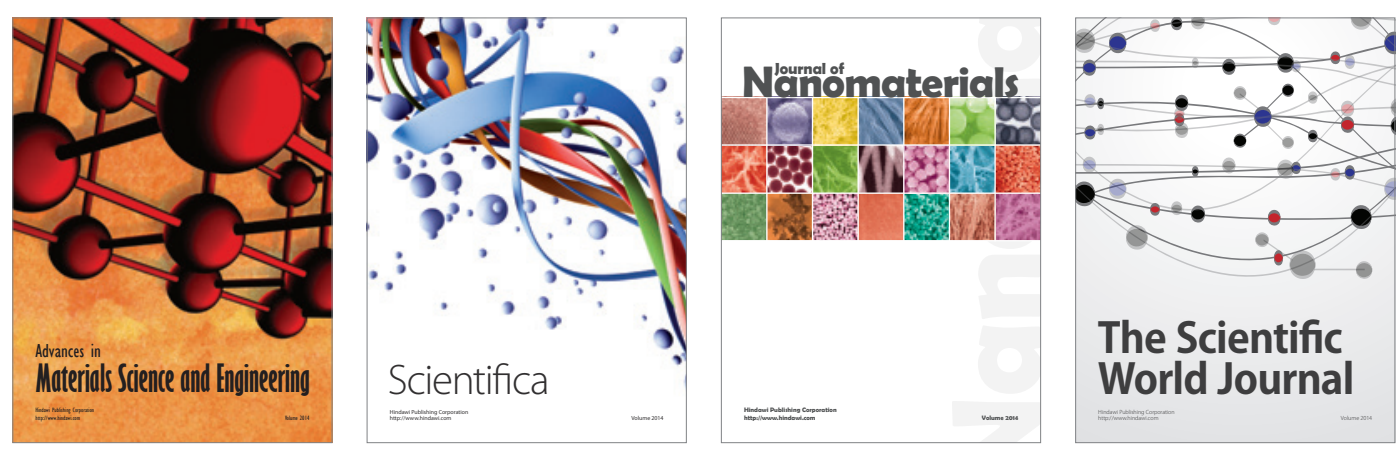

\section{The Scientific World Journal}
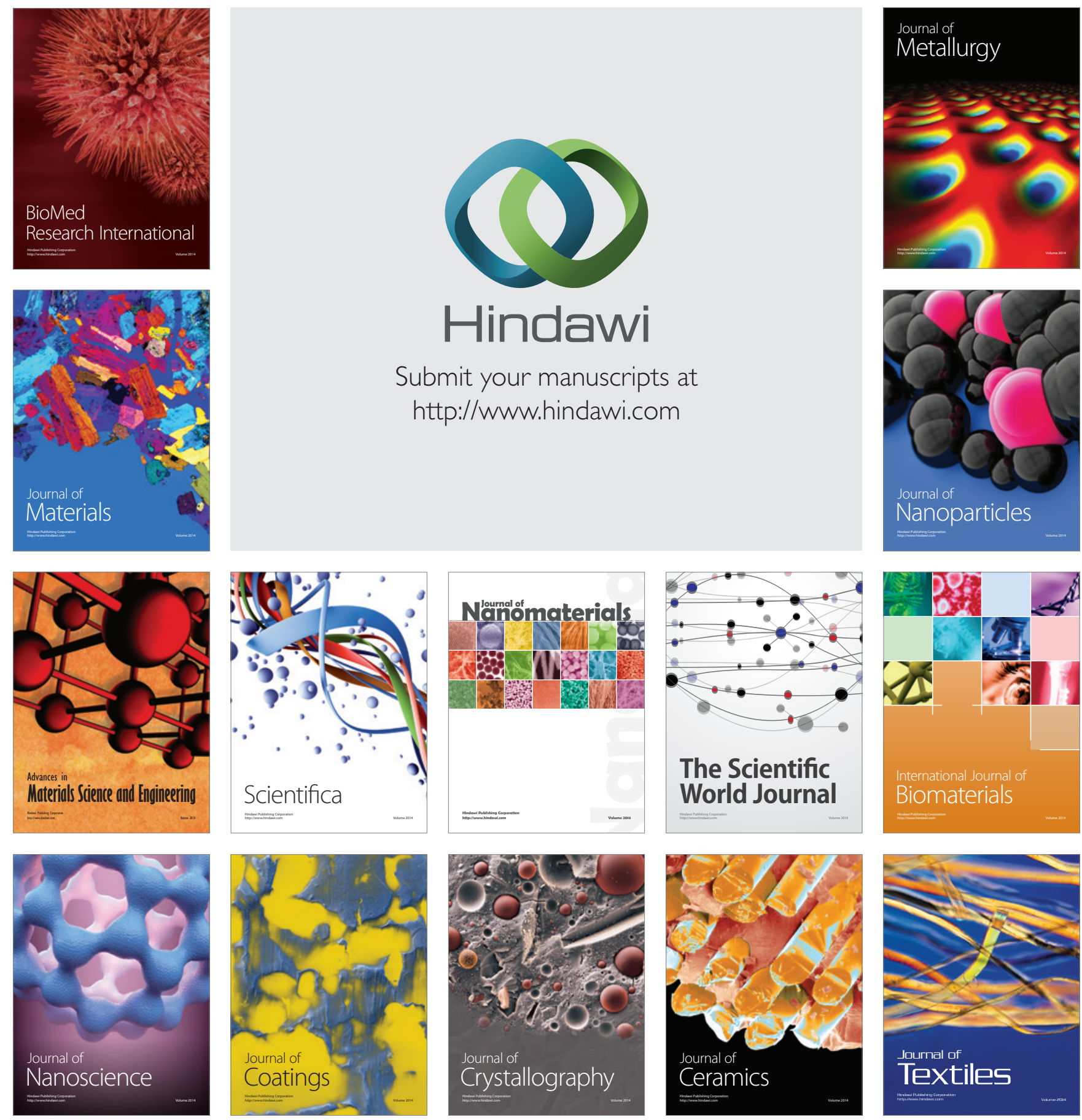